\title{
Subfunction Variation as the Source of the Expansion of the Preterit
}

\subsection{General}

This chapter provides an analysis of how the Preterit may have begun its expansion in Porteño Spanish. The chapter has the following structure.

First, rather than focusing on the global finding - the general decrease in the use of the Perfect-focus is on one subfunction, the experiential. The experiential function stands out, both in the oral and in the written sources, by appearing to be the first subfunction to be expressed by means of the Preterit, gradually spreading to other subfunctions.

Second, the empirical findings are connected to relevant theoretical assumptions, such as (i) the tense-like nature of the experiential (drawing on theoretical assumptions from Chapter 2), (ii) change occurring via microsteps that may, but need not, create macrochanges, and ultimately (iii) the key to understanding any semantic change lying in the interaction between speaker and hearer. In this view, language change arises in language use, through ad hoc speaker innovations, which count as change only as they are internalized by the hearer.

The variation in the experiential is argued to occur because of a two-step process; the Preterit is used to express experientiality as the specific time frame is assumed to form part of the semantics of the construction and becomes semanticized through a process of pragmatic strengthening (Traugott \& Dasher 2002); and the hearer interprets the Preterit as expressing CR related to the lack of temporal specification in the new use of the Preterit (Dahl \& Hedin 2000).

Third, I suggest that the abovementioned mechanisms create variation in the expression of the experiential, as it comes to be expressed not only by means of Perfects but also, crucially, by means of Preterits. "Variation" is here taken to mean inter- and intraspeaker variation, in a sense compatible with the concept of variation referred to by, e.g., Labov (2001: 80), in which it is stressed that variation may demonstrate a highly constrained pattern that closely determines the linguistic behavior of each speaker. Note that here, this variation is seen not as a carrier of social evaluation (although such a factor cannot be excluded), but as structured by age. 
Fourth, I conclude that the intertwined semantic relationship of the Preterit and Perfect categories leads to the frequent collapse of these categories into one. I also point to the fact that the semantic outcome of this collapse is the same, irrespective of which form leads in the expansion; the end result is a past/past perfective, reminiscent of what Dahl (1985: 139) describes as a tendency for the peripheral tense/mood/aspect categories to be attracted toward the center of the TMA system, thereby acquiring properties that are typical of the central categories.

Based on the available typological data, it appears to be the case that both forms are likely to expand, and I suggest there is no predictability as to which of the two expands. That expansion of the synthetic Preterit and the analytic Perfect are both likely is surprising, given the presumed preference for analytic forms (recall the principle of clarity; see Chapter 4). Still, the secondary sources of Latin American Romance languages clearly show that both forms may expand.

Fifth, and finally, I briefly discuss the question of contact. While innovation and reanalysis can be accounted for through language-internal processes, the further spread into society clearly has a social component. I will discuss whether the spread was due to (i) direct contact with Sicilian and covert prestige or (ii) postcontact simplification. It is unlikely that the novel use of the Preterit has occurred because of contact but likely that a social component has accentuated the spread.

\subsection{What Has Happened to the Porteño Spanish Preterit?}

Recall from Chapter 6 that the Porteño Spanish Preterit is used by all informants to express past with $\mathrm{CR}$. In these speakers, the category is polysemous and can be used to express two functions: ${ }^{1}$

1 I follow Traugott and Dasher (2002:11-16) in claiming that homonymy should be posited only when there is no clear semantic relation, no contrastive ambiguity between two meanings. I agree that this definition poses a methodological problem for the historical linguist: When have the meanings in a polysemous pair lost their relation? And when should the relation/ meanings be understood as homonymous? I will not go into further detail on this topic here, since it clearly does not apply to the status of the Porteño Spanish Preterit. 
(103) Past perfective

(22:22/11)

Después me fui una semana a Punta del Este

Afterwards REFL go.1SG.PRT one week to Punta del Este 'After that I went one week to Punta del Este'

(104) Past with CR

(22:26/11)

Conociste Punta del Este? Es muy lindo Punta del Este Know.2SG.PRT Punta del Este is very nice Punta del Este 'Have you gotten to know Punta del Este? It is very nice Punta del Este'

We observe that the Preterit can now refer to an occasion that is not temporally specified. Recall that generally, there is a restriction on the past; either it must be specified in time, or the speaker and the hearer must share the ability to refer to the occasion in question (Comrie 1985: 41): it must have an established reference point. This no longer applies to Porteño Spanish; see example (105):

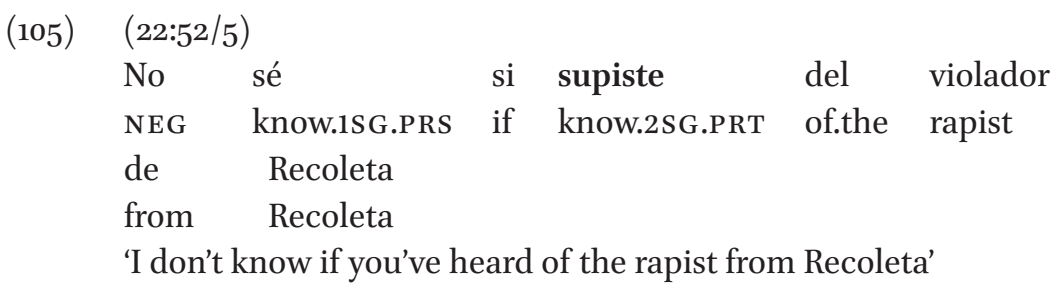

Following from the point above, the Preterit acquires the ability to appear without any temporal specification (contextual/adverbial). It can now be used to refer to past situations with unspecific time frame, as exemplified in (105) above.

Furthermore, it expresses token-focus, not only type-focus; that is, it can establish an event token as a new discourse referent, anchoring it in time and space (as opposed to anchoring a situation in a temporal domain):

(106) $\quad(06: 31 / 13)$

No fuiste a Bariloche? Qué lastima, para el

NEG go.2SG.PRT to Bariloche? What shame, for the

próximo viaje

next trip

'You haven't been to Bariloche? What a shame, for the next trip' 
It can be used to express current relevance, such as in a resultative, as in example (107):

(107) (30:35/3)

Voy recuperando partes mías que están quedaron go recovering parts mine that are Get.3PL.PRT perdidas como si no las pude desarrollar siento lost how if NEG them can.1SG.PRT develop feel 'I keep on recovering parts of me that are, that have been lost, as if I haven't been able to develop them I feel'

It can be used to express not only past with CR but also an imperfective notion, persistent situation:

(108) (23:38/3)

Está muy celosa siempre fue muy celosa de is very jealous always be.3SG.PRT very jealous of $X$ desde que nació $X$

$\mathrm{X}$ since that be.born.3Sg.PRT $\mathrm{X}$

'She is very jealous, she has always been very jealous of $\mathrm{X}$, since $\mathrm{X}$ was born'

Note, however, that the original function of the Preterit prevails, as seen in example (103) above:

- It continues to be used narratively.

- It continues to be used for token-focus.

- It continues to be used with specific-time reference.

As discussed initially, the possibility to express CR meaning with the Preterit makes the category polysemous. According to Traugott and Dasher (2002), semantic change cannot be studied without drawing on a theory of polysemy. This is because, as also discussed in 2.1.4, no change involves a simple A-for-B replacement, but rather it involves stages in which both $A$ and $B$ express the same content, or where, for instance, A expresses related, but distinct functions. Therefore, polysemy is often assumed to be a transitory stage in diachronic changes The Preterit category currently has two uses: 
(i) The perfective meaning: Situation is located to the past and is complete

(ii) The past with CR meaning: Situation is located to the past and has current relevance

Polysemy is the rule rather than the exception in natural languages, and this also follows from the approach taken here to verbal categories outlined in Chapter 2, in which category members are defined in terms of their similarity to a prototypical core member. As Croft (2012: 130) notes, grammatical aspect categories tend to be polysemous within a language and differ in their uses across languages. This means that one category can express different, related meanings. Kuteva and Kohan (2011), as en example, argue that the English simple past is polysemous and has the following functions:

- To locate an event at some point prior to the moment of speech

- To mark unreality, when combined with if

- To function as a pragmatic softener, when used with the English modals and verbs such as want, think, etc.

It is possible that the Porteño Preterit did express a wide range of meanings, such as experientiality, also before it began to change. As it changes, this polysemy becomes more pronounced.

Before continuing, I will, for the sake of clarity, explain again why the Porteño Spanish change needs a separate explanation. As I have shown, the Preterit's expansion can be defined negatively as follows:

- It is not grammaticalization (see 2.1.1.2).

- It is not a "different path" (see 2.1.1.2).

- It is not a traditional simplification (but see discussion in 7.7).

- It is not contact induced (although this might be an additional driving force, as discussed in section 7.8).

More importantly, the expansion of the Porteño Spanish Preterit cannot be accounted for by the same principles as those used to explain the expansion of a perfect. Recall from Chapter 4 that the generalization of a perfect to a past/past perfective (as seen in, e.g., French) is assumed to be a loss of specific meaning components and a subsequent generalization of meaning, since it is assumed that the CR component disappears (see Bybee et al. 1994). Nevertheless, it is worth questioning if the $\mathrm{CR}$ component is lost in French, is the remaining category then not polysemous? It is a paradox that the expansion of the Perfect is understood as a process of bleaching even though the end result arguably involves a broadening, or polysemization, of the category's scope. 
This understanding of the nature of the spread is concordant with the assumption that increased frequency of use leads to semantic bleaching. But in the present case, the $\mathrm{CR}$ component is added to the scope of the perfective, not lost. Bleaching and other frequency-driven processes do not apply. The processes involved in the Porteño Spanish change are discussed in further detail in section 7.7.1.

Change in the tense and aspect domain is often assumed to develop from the aspectual to the more temporal (Heine \& Kuteva 2007). Is the inclusion of CR readings in the Preterit's scope a development in the direction of temporality or aspectuality? The answer depends on how one is to define the features that are added to the Preterit's scope but is difficult to reach because the definitions of a perfect and of a CR component are themselves unclear. In section 2.2, I showed that the perfect is generally agreed upon as having four distinct, but related, subtypes (persistent situation, experiential, resultative, and recent past) that share the semantic notion of $\mathrm{CR}$. It is, however, notoriously difficult to explain exactly what this component entails. It appears, though, that the addition of a CR component has more in common with aspectual changes than with temporal ones. CR clearly is not a temporal notion, and I therefore understand the expansion to have more in common with aspectual than temporal change.

First and foremost, however, the Preterit's expansion is a change in grammatical meaning. The Preterit category in Porteño Spanish changes in scope. The restrictions previously attached to it no longer apply, as seen earlier in this section. It appears that pragmatic and dialogical forces are able to trigger both the expansion of a perfect (probably because of a CR component, as observed above) and the expansion of a Preterit, most likely because of inferences about the semantics of the experiential category. I now turn to the details of the model of the expansion.

\subsection{Creating a Model for the Preterit's Expansion}

As discussed in Chapter 2, a simple yet illustrative sketch captures the intermediate stage in which a new and an old construction coexist:

$\mathrm{A}>[\mathrm{A} / \mathrm{B}]>(\mathrm{B})$

FIGURE 12 A formalization of linguistic change (from Norde 2009: 16).

A more nuanced model is proposed in Enfield (2003): 
TABLE 20 Stages in semantic change (based on Enfield 2003: 29)

\begin{tabular}{lllll}
\hline & Stage I & Stage II & Stage III & Stage IV \\
\hline Form & $\mathrm{f}$ & $\mathrm{f}$ & $\mathrm{f}$ & $\mathrm{f}$ \\
Meaning & 'p' & 'p' $(+>$ ' 'q') & 'p', 'q' & 'q' \\
\hline
\end{tabular}

None of these figures fully capture the expansion of the Preterit category (but note that they could capture the change in the specific subfunctions, such as experiential). Why? In Porteño Spanish, we are dealing with a category that falls into disuse, not one that appears and subsequently coexists with a previously existing one in a transition phase. This demise is captured in a modified version of Enfield's model:

TABLE 21 Modified version of Enfield (2003); competing forms, Porteño Spanish

\begin{tabular}{|c|c|c|c|c|c|c|c|}
\hline \multirow[b]{2}{*}{ Form } & \multicolumn{2}{|c|}{ Stage 1} & \multicolumn{2}{|c|}{ Stage 2} & \multicolumn{2}{|c|}{ Stage 3} & \multirow{2}{*}{$\begin{array}{l}\text { Stage } 4 \\
\mathrm{f}^{2}\end{array}$} \\
\hline & $\mathrm{f}^{1}$ & $\mathrm{f}^{2}$ & $\mathrm{f}^{1}$ & $\mathrm{f}^{2}$ & $\mathrm{f}^{1}$ & $\mathrm{f}^{2}$ & \\
\hline Meaning & $\mathrm{p}$ & $\mathrm{q}$ & $\mathrm{p}$ & $\mathrm{q}(+>\mathrm{p})$ & $\mathrm{p}$ & $\mathrm{p}, \mathrm{q}$ & $\mathrm{p}, \mathrm{q}$ \\
\hline $\begin{array}{l}\mathrm{f}^{1}=\text { Perfect } \\
\mathrm{f}^{2}=\text { Preterit }\end{array}$ & & & & & & & \\
\hline
\end{tabular}

What is remarkable in this modified model is the nature of stage 4, in which two forms are reduced to one, while the complex meanings ( $p$ and $q$ ) are expressed by means of the same form, $\mathrm{f}^{2}$. It is q's inclusion in the expressed form $\mathrm{f}^{2}$ that should be highlighted.

So far, I have illustrated the broadened scope of the Preterit as it acquires a CR function. Now, I approach the task of providing an explanation for this change. Ideally, a model should be able to (i) account for the way in which the Preterit becomes able to express $\mathrm{CR}$, (ii) suggest a semantic turning point, and ideally, (iii) also shed light on related developments in other languages.

The model proposed below suggests answers to all three elements. In addition, it creates a plausible hypothesis of the status of other Latin American varieties and their highly heterogeneous Perfect/Preterit distributions. 


\section{7·3.1 Subfunction Variation and the Experiential}

Chapter 6 provided evidence for the spread of the Preterit and the demise of the Perfect. In addition, a salient feature, that of substantial variation in the expression of past with $\mathrm{CR}$, was identified. In age group I, this variation is found in all subfunctions, but in older written sources and in the HABCULT corpus, in addition to UYCORP, this variation is centered on the experiential. Clearly, this subfunction stands out because of its frequency: it appears more frequently than the other subfunctions in the material, probably because of the nature of the interviews (informants tended to talk about their prior personal experiences, which are typical experiential generators). More importantly, however, it stands out as the locus of variation in the oldest sources.

These distributions of Perfect and Preterit show that the variation found in the expression of the two subfunctions in age group II practically disappears in age group I. However, the variation found in age group II does not provide any clear hints as to the turning point of the change; it illustrates variation in the expression of experientiality, but also to some extent in the expression of resultativity and persistent situation.

Other sources do provide clear evidence for the early expansion of the Preterit to convey experientiality. First, the UYCORP sources suggest (despite their low overall frequency) that where there is variation, the variation is localized to the experiential.

Second, the written corpus shows variation in the experiential, to a radically lesser extent than in the other subfunctions.

Third, in the old written sources (presented in 6.8)—representing the earliest stage of Porteño Spanish to be found in this study, a stage that shows clear variation in the experiential — the Preterit already at this stage had made its way to the written language, expressing experientiality in $52 \%$ of the relevant tokens (15[29]). Note also that persistent situation is never expressed by means of Preterits (but by means of Present constructions in $14 \%$ of the contexts (4[29]) tokens). For details on these constructions, see Chapter 2; see also Burgos (2004). Crucially, therefore, we observe variation in the expression of experientiality.

The variation between the two forms in Figure 13 is absent in the expression of persistent situation, as seen below in Figure 14. In persistent situation, there is variation, but this variation occurs between Present constructions and the Perfect (4[29] tokens). 


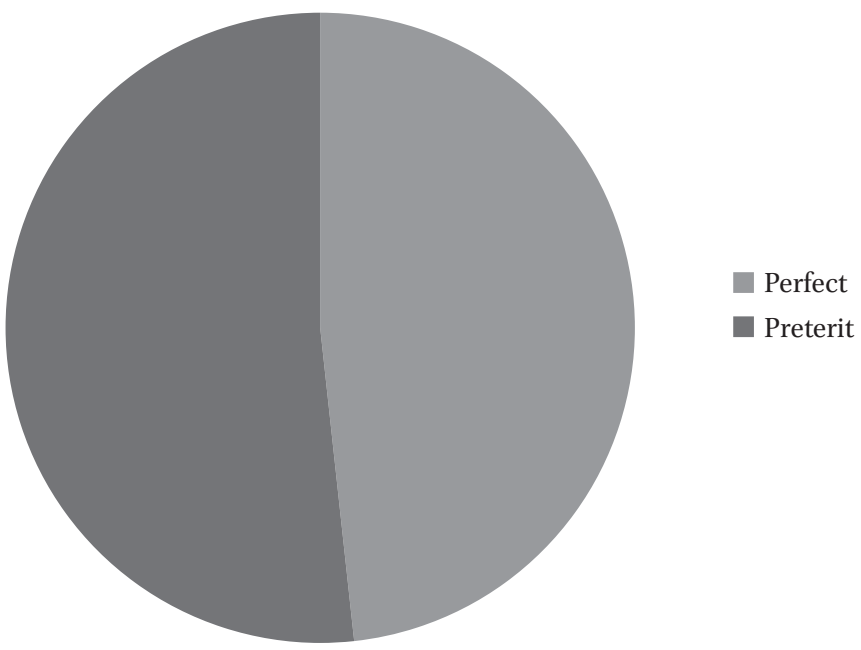

FIGURE 13 Expression of experientiality in HABCULT, introductory texts.

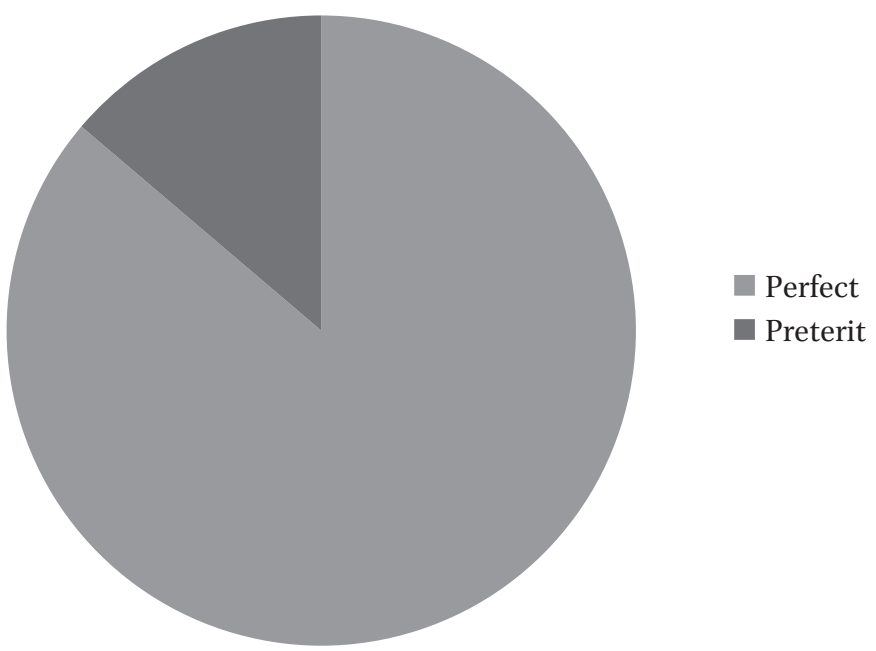

FIGURE 14 Expression of persistent situation in HABCULT, introductory texts.

These early sources provide particularly telling evidence in support of the experiential's being the locus of the change. This evidence is especially telling since these tokens are extracted from a formal written source, which is expected to be more conservative in the acceptance of new construction. We can assume that the experientiality had occurred in speech before it appeared in these written sources, making it likely that this variation was generated early, perhaps in the middle of the 2oth century. 


\section{7·3.1.1 What About the Other Subfunctions?}

It is worth mentioning, however, that the HABCULT introductory texts include no data regarding recent past or resultative functions. Because of this gap, it is not possible to discard the possibility of there also being variation in these subfunctions at this stage. In Chapter 6 it was shown that in age group II, all recent past tokens were expressed by means of the Preterit. It might well be that recent past was early in the expansion; it is simply not deducible from the corpus whether this is the case. As I shall discuss further below, this function is indeed often assumed to have tense-like qualities (recall also from Chapter 2 that its relevance is taken to be due to temporal recentness; see Croft 2012: 142-143; Klein 1994: 113), and because of these qualities, it would not be unexpected for this function to have expanded before, for instance, persistent situation. Dahl and Hedin (2000: 396) also note that recent past is expressed by means of past in many languages.

As for the resultative, it is indeed expressed by means of both Preterits and Perfects in age group II, but there is no similar variation in written sources or in UYCORP. In these sources, the resultative is mostly expressed by means of the Perfect; HabCUlt interviews include 24 Perfects and no Preterits expressing resultativity (Table 18). UYCORP includes six Perfects and one Preterit expressing resultativity (Table 17). There is no typological or theoretical support in favor of the resultative's early expansion. Based on theoretical assumptions and typological distribution, therefore, it is less likely that the resultative was the first to expand.

Overall, the data are suggestive but, as I shall show in the next section, strongly supported by cross-linguistic findings and theoretical considerations.

\subsubsection{Experientiality Expressed Cross-Linguistically}

Variation, different ways of saying "the same thing" (Croft 2010: 7), is expected in any language. Here, variation is seen as both an origin and an end point of change (Croft 2010). In the following section, I provide further evidence that the subfunction that is first expressed by means of Preterits is the experiential.

The findings from Uruguayan and Argentinean Spanish suggest that the early expansion of the Preterit occurred in the experiential function. If this expansion occurs as a result of usage-based mechanisms, it is expected that similar developments are to be found in other languages as well. Recall from Chapter 2 that in a usage-based framework, linguistic material is viewed as formed by mechanisms that are common to speakers of all languages. This prediction is indeed supported by typological evidence-we do find experientials expressed by means of Preterits in other languages that originally had a separate Perfect category. 
McKenzie (1999: 39-40) notes that the "simple past" (his term for the Preterit) in certain varieties such as Galician and Asturian, as well as in varieties in large parts of Latin America, appears in experiential use (existential in his terms; see also Chapter 2 for an overview of the different terms). In this use, the Preterit refers to a time prior to the time of speech, in which an event of some type occurred, as in (109):

(109) Fuiste alguna vez a México?
Go.2SG.PRT any time to Mexico
'Have you ever been to Mexico?'

(McKenzie 1999: 40)

Rodríguez Louro (2009: 108), however, states that the experiential is overwhelmingly expressed by the Perfect in Argentinean Spanish (see also 6.3.2.4). This conclusion is surprising, given the fact that in her data from young participants, experientiality is expressed by means of the Preterit in 88.5\% (100[113]) of all contexts, the remaining being expressed by means of Perfects. Among the young speakers of Rodríguez Louro's study, experientiality is thus overwhelmingly expressed by means of Preterits.

Henderson (2010: 63) notes that experientiality frequently is expressed by means of Preterits in Latin American varieties of Spanish. In Brazilian Portuguese, experientiality is expressed by means of Preterits. Henderson, citing Paiva Boléo (1936), illustrates this use in Brazilian Portuguese with a hypothetical example: if the son in a family is sent away to study, and the mother is asked by family members whether she has heard from him, this question would be expressed by means of either (110) or (111) in Brazilian Portuguese (Henderson 2010: 63):

(110) Então filho escreveu?

So son write.3SG.PRT

'So has son written?'

In example (111), the past with CR is expressed by means of the Preterit and an adverb já 'already', cross-linguistically a common source of perfects (Dahl 1985: 129).

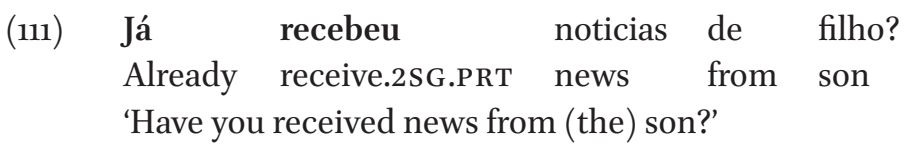


Remarkably, in Brazilian Portuguese, the Perfect is not used to express experientiality; it is employed to express persistent situation only. The following sentence, from Howe (2013: 77), therefore has persistent situation interpretation:

(112) Eu tenho morado no Rio por três anos
I live.1sG.PRs.PRF in Rio for three years
(i) 'I have lived in Rio for three years' (persistent situation)
(ii) 'I Thavelivedin Rio for three years/inathree-yearperiod'(experiential)

In Brazilian, unlike in languages where the perfect has a more canonical use, interpretation (ii) is unavailable. This means that the Perfect is restricted to use in persistent situation function. This tendency also holds for Galician, in which the Perfect is rare, and when it is used, it is used only in contexts denoting resultativity or persistent situation (Squartini \& Bertinetto 2000: 410), thus making it likely that the first two functions expressed by means of the Preterit were experientiality and recent past. Note that these two are also the functions that are placed closest to the past, as discussed below in section 7.3.2.1.

\subsubsection{Additional Evidence}

As briefly mentioned in Chapter 2, several approaches to the Perfect/Preterit distinction account for the competing relationship between the two and the ability of both to enter each other's domain. For example, Dickey (2001: 15) argues that the English Preterit, a simple past tense, (which is known to be used frequently in a CR function; see, e.g., Elsness 1997) is ambiguous. In this view, the simple past has two senses. ${ }^{2}$ One spells out a genuine, anaphoric past tense, which refers directly to past moments in time. The other-relevant for the present purposes - is an interpretation with an existential quantificational force, which does not refer to previously mentioned times (remember that "existential" is another term for experiential). Dickey (ibid.) also notes how in a language such as German (which variety is not specified), the simple past requires an explicit reference in preceding discourse to be felicitous. If no such context is present, such as in out-of-the-blue contexts, the Perfect is required. It is not impossible that a similar constraint has held in Porteño Spanish and that this former requirement now exists only as relics in the language of young and adolescent speakers, as discussed in section 6.3.5. This might then explain why some experiential tokens are retained in the language of speakers who otherwise have replaced all subfunctions with the Preterit, such as in the following examples:

2 This is referred to as quantificational and referential tense, and this approach will not be treated here. 
(113) (01:04:40/8)

Y que has hecho aparte de estudiar?
And what do.2SG.PRS.PRF apart of studying
'And what have you done apart from studying?'

(114) (01:07:25/8)

Noruegos acá no te has comunicado con

Norwegians here NEG you communicate.2SG.PRS.PRF with noruegos acá?

Norwegians here

'Norwegians here you haven't been in contact with Norwegians here'

Similarly, Schaden (2009) provides an analysis in which he relies on the concept of markedness between the two forms. He discusses the competing relationship between Perfects and Preterits and argues that in certain languages, such as English and Spanish, the Preterit can always be used whereas the Perfect is the marked form, restricted to very few contexts. ${ }^{3}$ In languages such as French and German, he argues, the situation is the opposite. Here, the unmarked form is the Perfect. He further argues that the restriction most likely to undergo contextual manipulation is what he calls lifetime effects (the possibility of reiteration of the situation in question; see section 2.2.7.3), typically associated with experientials, as in the examples he cites (ibid.: 36; see also Portner 2003: 464):

(115) A: Which Nobel Prize laureates have visited Princeton?

B: Let's see... Einstein has (visited Princeton), Friedman has (visited Princeton)

(116) Shakespeare has influenced every known writer to some extent

Clearly, these phrases illustrate an opposite development to that in Porteño Spanish, namely the extensibility of the Perfect to contexts typically outside its scope. In this case, the Perfect is used when referring to actions that are nonreiterable (Einstein can no longer visit Princeton). However, it should be noted that these examples clearly illustrate the flexibility and semantic proximity between perfectives and experientials expressed by means of Perfects.

Schaden's account largely ignores diachrony, though, and the developments that have created the current synchronic systems in the languages

3 Schaden takes a marked form to mean a form that needs to be justified and that triggers a pragmatic reasoning process (2009: 29), as opposed to the default form, which does not have to be justified. The concept of markedness will not be further discussed here. 
he describes. ${ }^{4}$ In addition, Schaden (ibid.: 39 ) states that the restrictions on the Perfects in languages like English and Spanish are generally seen as indications that these tense forms have not yet acquired a past tense-like status. This scenario is clearly not valid for all languages in which such processes occur, and the author makes no further comment on the diachronic expansion of the Preterit.

\subsubsection{Experiential: Typological Distribution and Defining Features}

The experiential offers a way of referring to a past action without referring to a specific occurrence and is thus characterized by nonspecific-past time reference (Lindstedt 2000). Crucially, the experiential is more indirectly relevant to the present state of affairs than, for example, the resultative is; the relevance is more indirect and abstract, even psychological in nature. The CR component in experiential perfects is thus weaker than in, for example, resultative perfects, in which the result state is more tangible (but cf. Brinton 1988 for an opposing analysis). ${ }^{5}$ Even more importantly, the experiential is more tenselike than the resultative perfect, being an indefinite past tense that typically occurs in questions and negated assertions with ever-like adverbials. However, current relevance and experientiality do not exclude each other, and when expressed, elements of both can be discerned (Lindstedt 2000: 369). As we shall see later in this chapter, the experiential may appear without temporal specification, and when it does, it is the $\mathrm{CR}$ meaning which comes into play (Dahl \& Hedin 2000).

Table 22 summarizes the above-listed points and their relation to prototypical experiential and perfective categories.

4 In a recent article (Schaden 2012), Schaden proposes an explanation for the diachronic development toward expansion of perfects, based on the idea of inflation due to speakers overestimating the current relevance content of their utterances. Change is thus viewed as a long-term consequence of language use or, in Schaden's words "speaker-hearer interaction and the biases that act upon them" (ibid.: 261).

5 However, according to Brinton, tangibility is a result within the realms of experience, memory, and feeling. The experiencer has been affected internally by the situation and bears the result of that change. 
Experiential Perfective past

\begin{tabular}{lll}
\hline May appear without spatiotemporal specification & Yes & No \\
Can be used narratively & No & Yes \\
Expresses type-focus & Yes & No \\
Expresses token-focus & No & Yes \\
Has restrictions on reiterativity & No & No \\
Has restrictions on use of adverbials & Yes & Yes \\
Includes CR component (aspect-like features) & Yes & No \\
Can be used with specific-time reference & No & Yes \\
(yesterday, in 1990, etc.) & &
\end{tabular}

Remarkably, as the Preterit expands in Porteño Spanish, the Preterit comes to cover all uses associated with both experiential and perfective (in the majority of age group I speakers).

\section{7·3.2.1 Functional Overlap}

As I showed in Chapter 2, there is no consensus as to whether the perfect is an aspect or a tense-or neither. This lack of consensus may be triggered by the fact that perfects may be used to express tense-like states but they also convey additional information, here assumed to be CR. In any event, some uses of perfects lie close to purely temporal interpretations, and there clearly are contexts in which the perfect and the past perfective/past may be used more or less interchangeably.

We have also observed how categories have nondiscrete boundaries and are gradient in nature. Michaelis (2006: 4) refers to the way in which tense and aspect may interact with the same system as functional overlaps. One such overlap, she argues, is exemplified in the use of the Perfect in English and phrases such as (117), which may have purely temporal interpretations:

\section{(117) We've lost our lease}

Dahl (1985: 139) similarly admits that despite differences (such as the perfect's typically not being used narratively), there is a considerable overlap in the distribution between the perfect and the perfective. In Dahl's view, this overlap may have to do with the two categories' historical relation (as discussed in 4.2). According to Howe (2013), the functional overlap between the Perfect and 
Preterit accounts for their synchronic distribution in, for instance, Peruvian Spanish. Comrie (1995) notes that perfect and simple past are in general not substitutable for one another without clearly changing the speaker's communicative intent. However, he argues that there are examples in which, even in the presence of continuing relevance, English prefers the simple past, noticeably with explicit time adverbials, such as in (118), an illustration of the intimate relationship between the two:

(118) 'Have you seen Amy? Yes, I saw her two hours ago'

Elsness (1997: 26) similarly notes that what he refers to as "preterites" (a term he does not capitalize; meaning simple pasts) may be used without temporal specification. While Elsness argues that "preterites" normally require a temporal anchor, he notes that this anchor does not have to be expressed linguistically, as in the following examples:

(119) My watch-trap snapped

(120) The candlestick overturned

Here, in the absence of a temporal specification, Elsness argues that the Preterit expresses immediate past. This notion of immediate past may be compatible with the notion of recent past - and hence not with the notion of experientiality. It is surely possible that such phrases may have been crucial to the change in Porteño Spanish as well, but unfortunately, there is no evidence to either confirm or disconfirm such a claim in the data material, as discussed in 7.3.1.1.

As discussed in Chapter 4, in a usage-based framework, it is often stressed that the overlapping relationship between perfects and past/past perfectives has diachronic origins; both perfects and pasts/past perfectives are assumed to develop from similar lexical sources and to go through stages signaling anteriority. In the usage-based framework focuses on the assumption that the diachronic relation between perfects and pasts leads to a synchronic, semantically intertwined relationship, as suggested by Dahl above. Ritz (2012: 882) similarly argues that the perfect must be studied together with the past perfective because they are intimately intertwined diachronically and synchronically. Bybee (1985: 162) also notes that "anterior" (her term for perfect) and past/past perfective may not be independent, owing to an overlap in their conceptual domains, which leads to a diachronic relation between them. Croft (2012: 143) suggests that the overlapping semantics are due to the diachronic development between the different categories, and suggests the following rankings from closer to the past to closer to the present: 


\title{
More past
}

\author{
$\uparrow$
}

Immediate past perfective, perfect of recent past

Experiential perfects

Result/state perfects

$\downarrow$

More present

FIGURE 15 Ranking from past to present after Croft (2012: 143).

Croft's model builds on a multidimensional scaling of Dahl's prototypes (1985; discussed in Chapter 2), and the results presented above illustrate the conceptual continuum in the spatial model between past perfective, perfect and its relatives. Remarkable here is the absence of persistent situation. This absence is due to the fact that in Dahl's questionnaire, persistent situation occurs in the present imperfective cluster, which is compatible with the discussion in 2.2.7.2-persistent situation differs drastically from the other subfunctions typically expressed by means of Perfect. As a whole, Croft's illustration provides a clear illustration of the extent to which the different subfunctions are closer to present or to past tenses, but differs from other accounts in that he ranges recent past as the most tense-like.

\subsubsection{Examples from Porteño Spanish}

The first example stems from the HАВCULT corpus and shows the alternations between Perfect and Preterit in informant A. Below, I suggest that the structure of this variation (phrase-initial Perfect, Preterit after past context is established) may be the locus of the change in Porteño Spanish. These examples illustrate not only intraphrasal variation between the two forms but also intraspeaker variation.

(121) HABCULT: 333

Hace tres años que no pisa la calle, que no Make three years that NEG step the street that NEG ha querido salir. desde que estamos acá fue want.3SG.PRS.PRF go.out since that are here go.3SG.PRT una sola vez al oculista, nada más. Y ya one only time to.the oculist, no more and already después no volvió a salir. after NEG return.3SG.PRT to go.out

'It's been three years that he doesn't set foot on the street, that he has not wanted to go out. Since we are here, he has been once to the oculist, nothing more. And after that he hasn't gone out again' 
(122) HABCULT: 333

Extraña mucho, sí. Y claro, imagináte, para él misses much yes and clearly imagine for him hasido un cambio dejar el consultorio be.3SG.PRS.PRF a change leave the office 'He misses it a lot, yes, and yes, sure, imagine, for him it has been a change to leave the doctor's office'

Examples (123)-(124) clearly illustrate an alternation between Perfect and Preterit in experiential function. Note that this is a speaker who shows variation in no other subfunctions than the experiential:

(123) $\quad(05: 14 / 17)$

Pero nosotros hemoshecho bondiola que es muy But we make.1PL.PRS.PRF bondiola that is very parecido lleva el mismo proceso similar takes the same process

'But we have made bondiola that is very similar, takes the same process'

(124) (05:55/17)

Nosotros hicimos nos quedó riquísima la bondiola We make.1sG.PRT us turn.out very.good the bondiola 'We have made bondiola it turned out great for us the bondiola'

The examples provide illustrations of the prevalent subfunction variation found in the same speaker. It appears uncontroversial, therefore, to claim that the overlapping relationship between a perfect and a perfective allows for the expansion of the former. However, considering the heterogeneity of the Romance Perfects (as well as the Perfects of other language families; see section 4.3.1.1), it should be noted that the instability appears to be on the level of the distinction and on the level of form; the grammaticalized expression of the perfect appears to frequently disappear, but it is not predictable which of the forms will absorb the old perfect's meaning. What is clear from the data of these varieties is that dialogic and contextual forces may motivate both the expansion of a perfect and the expansion of a Preterit. But how does such an expansion come about?

Based on the abovementioned empirical and theoretical considerations, it is likely that experiential constructions lead the change, because they (1) are the most tense-like of subfunctions, (2) have an abstract CR component, and (3) are generally defined temporally by contextual clues (temporal adverbs and also common ground/presuppositions). 


\subsection{How is the CR Reading Arrived at? The Creation of the Subfunction Variation}

In the preceding sections, we have observed that there is substantial variation in the expression of experientiality in Porteño Spanish, as well as in other Spanish varieties. It also appears clear that the intertwined relationship between the Preterit and the Perfect easily enables one to enter the other's domain. Still, it is necessary to account for the microsteps taken as the Preterit acquires the possibility to express past with CR. How does this change in semantic scope come about? In this section, I suggest a two-step process for how the new interpretation is arrived at. First, I argue that a speaker-induced pragmatic strengthening allows the Preterit to express CR. This pragmatic process easily allows the Preterit to enter into the Perfect's domain, as I have shown, because of their initially intertwined semantics. Second, I argue that the hearer easily arrives at the CR interpretation because of the lack of temporal specification in the speaker's new use.

\subsubsection{Pragmatic Strengthening}

Even when a tense/aspect marker is used, contextual considerations play a substantial role in determining the intended temporal reference of a situation (Nicolle 2012). The scope of the past/past perfective, for instance, is contextually determined-either explicitly by the presence of temporal adverbials/ quantifiers or by information derived from the previous discourse or extralinguistic context; as Comrie (1995) argues, it is underspecified. Consider the hypothetical examples (125) and (126), in which (125) is determined by discourse context:

(125) Mi hermano vivió en NYC en los noventas.
My brother live.3SG.PRT in NYC in the nineties
Yo lo visité
I him visit.1SG.PRT
'My brother lived in NYC in the nineties. I visited him'

Example (126), however, is determined by a temporal adverbial, here en el 1995 'In 1995': 


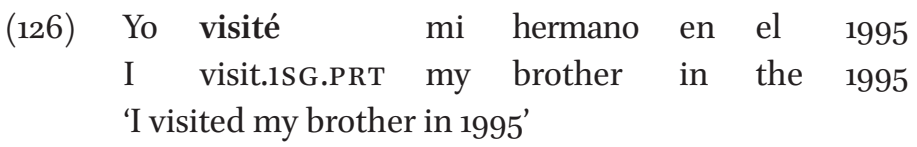

As we have observed, Porteño Spanish now allows for these types of phrases, without temporal specification (explicit/indirect), expressing CR:

(127) Lo visité $\quad$ a mi hermano
Him visit.1SG.PRT to my brother
'I have visited my brother'

Note that in this example, the lack of temporal specification allows for a CR interpretation. While isolated, it is ambiguous with a past perfective reading; this isolation, however, is precisely where the $\mathrm{CR}$ interpretation arises. I return to this in section $7 \cdot 5 \cdot 1$ below.

\subsubsection{Transitional Contexts}

In this section, I point to an intermediate stage in the expansion of the Preterit. This stage illustrates the further expansion of the Preterit, and can be labelled a transitional context, in line with Fried (2009: 277), who states that it is important to identify the features of such transitional, intermediate patterns because of the role these they play in the emergence of new structures.

The contexts in which the Preterit appears in an already established past context are transitional contexts, and I hypothesize that speakers in these contexts use the Preterit instead of the Perfect because they infer that the previously established past context is part of the intended meaning and that their recurrent use makes them associated with a specific form - in this case, with the Preterit. As we shall see, this analysis captures how experiential meaning arises in transitional contexts.

There is a difference in the interpretation of forms that appear with temporal specification and forms that do not. Dahl and Hedin (2000: 387), for instance, note that it is unexpected to find type-focusing sentences (that is, sentences without specific time reference) in out-of-the-blue contexts. It appears plausible, considering evidence from the behavior of the two categories in other languages, that the phrases that serve as transitional contexts in Porteño Spanish are noninitial. I now turn to evidence from other languages.

Comrie (1995: 154) provides crucial insights on this topic in a discussion of the German Perfect. He notes that there are instances in which a Perfect and a Preterit can be used interchangeably, and he argues that one such example is situations in which the Perfect introduces an out-of-the-blue context, 
while the Preterit is used once this context is established. Comrie (ibid.: 155) states that: "it is more plausible for the addressee to be led to link later events to the preceding event, and the use of the Präteritum (pflegte, sa $\beta$ ) indeed leads the addressee in this direction." Again, the speaker chooses the Preterit over the perfect because the reference of the Preterit is linked to the situation introduced by the perfect. This is precisely what I suggest for Porteño Spanish: the speakers choose the Preterit when there already exists a link to a temporal reference.

In such transitional contexts, the novel use of the Preterit can arise either through a pragmatic strengthening and/or simply through the lack of explicit temporal reference, which may lead to a current relevance interpretation. Example (128) below shows a transitional context that precisely enables, but does not necessarily give rise to, a new interpretation. This is what we observe in the last sentence in example (128); there is variation between speakers, as the reanalysis expressed in informant 17 clearly has not yet occurred in informant 15 .

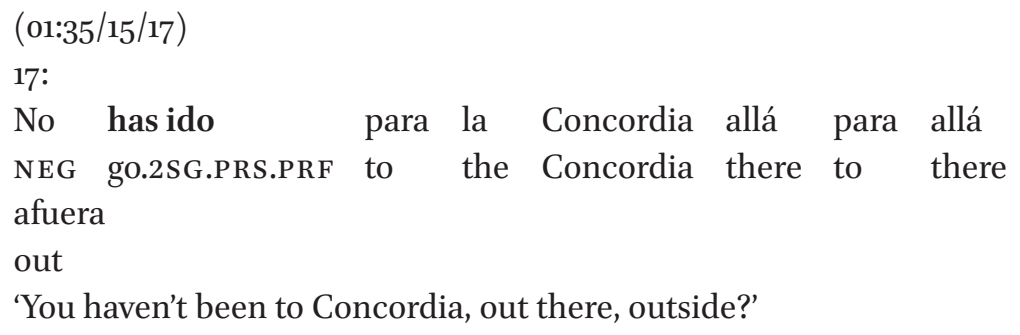

Note how the speaker first uses the Perfect and later substitutes it with the Preterit. What distinguishes these two sentences? Semantically, they both express experientiality. When it comes to information structure, however, the first sentence can be seen as establishing a past context. It is possible that in the second sentence, the speaker infers that the hearer is aware of the preestablished past context, and therefore employs the more general Preterit. 
Note that it is natural to expect phrase-initial tenses/aspects to be anchored in time (see, e.g., Dahl \& Hedin 2000: 389-390; Comrie 1995: 154).

Why are such examples found in the experiential and not, say, in the persistentsituation function? Here, it is assumed that the speaker may use the Preterit in this novel way because of the abstract CR component in the experiential. Thus, this predicts that we would not expect to find persistent-situation tokens in the transtitional contexts, and this prediction holds true; recall from Figure 14 that persistent situation shows no variation of expression in HABCULT texts.

\subsubsection{Further Evidence for Transitional Contexts}

As discussed in Chapter 6, data from age group II provide evidence to understand the change in question, because these speakers here alternate between using the Perfect and the Preterit to express past with CR.

The examples from this group illustrate a transition phase, because these speakers use both the Preterit and Perfect to express past with CR. Again, the data illustrate experientials expressed by means of the Preterit after a past situation already has been established. Note that these speakers exhibit no intrasentential variation, as do the HABCULT speakers above:

(129) (21:00/11)

El hotel se llama Arapey Hotel Resort. Y ahí estuve (...) Después me fui una semana a Punta del Este

'The hotel is called Arapey Hotel Resort. And there I was (...) After that I went one week to Punta del Este'

Conociste Punta del Este? Es muy lindo Punta del Este Know.2SG.PRT Punta del Este is very nice Punta del Este 'Have you gotten to know Punta del Este? It is very nice Punta del Este'

The same holds for (130). In this sentence, the speaker uses a Preterit to express experiential after the past context has been established through pictures illustrating a past journey:

(130) (Interviewer and informant looking at pictures from the interviewer's travel to India)

(13:19/9)

$\mathrm{Si}$ estuvo en India

Yes be.3sg.PrT in India

'Yes, she has been in India' 
Similarly, example (131) below shows the Perfect establishing a context, followed by the experiential Preterit. This example is particularly telling because the interviewer uses the Perfect to express experientiality (he vivido en Italia un tiem ...) while the informant answers using the Preterit (viviste en Italia). This example illustrates how the speaker employs the Preterit to respond to an established past context, and also the clearly intertwined relationship between the two forms to express the same functions:

(131) (34:16/12)

$\begin{array}{lllll}\text { He vivido } & \text { en Italia } & \text { un } & \text { tiem } \\ \text { Live.1SG.PRS.PRF in Italy } & \text { a } & \text { time } \\ \text { 'I have lived in Italy for a while' } & & \end{array}$

Ah viviste en Italia?

Ah live.2SG.PRT in Italy

'Ah you've lived in Italy'

Example (132) also shows a preestablished context followed by the Preterit to express experientiality (ella vivió en Dolores).

$(132) \quad(35: 48 / 10)$

(Informant's brother imitating Uruguayan Spanish)

I: Me hace acordar a como hablan en Dolores

'It reminds me of how they speak in Dolores'

Ella vivió en Dolores en el Uruguay en

She live.3sG.PRT in Dolores in the Uruguay in

el interior

the interior

'She has lived in Dolores in Uruguay in the interior'

Note that this informant uses the Perfect too in these constructions, as in example (133):

(133) (14:55/19)

No hasido a Uruguay, Tony?

NEG go.2SG.PRS.PRF a Uruguay Tony?

'Have you not been to Uruguay, Tony?' 
These examples suggest that age group II speakers find themselves in a transitional phase. For these speakers, the new use of the Preterit is not yet favored in any clear contexts but appears to coexist with the Perfect randomly. This variation further indicates that the Preterit use to express past with CR is indeed novel, and we observe a coexistent variation of the two types in these informants.

\subsubsection{Age Group I: The Change Has Taken Place}

In age group I, the novel use of the Preterit has conventionalized and appears in all the subfunctions previously associated with the Perfect. On a general note, in the language of the young informants, in which the novel use has taken hold within the already existing system, the Preterit can now appear phrase initially, "out of the blue," and conveys past with CR, without a temporal location being previously identified:

(134) (27:47)

Viste el hotel Rivadavia no sé si lo conoces

See.2G.PRT the hotel Rivadavia NEG know if it know

'Have you seen the hotel Rivadavia? I don't know if you know it'

Example (135) similarly provides a series of uses of Preterit to express token-focus:

\section{(135) (21:55/7)}

Viste que hay mujeres que tienen suerte a mi
$\begin{aligned} & \text { See.2SG.PRT that are women who have luck to me } \\ & \text { todo me costó }\end{aligned}$ bueno estudié
everything me cost.3.SG.PRT well study.1.SG.PRT that
que quise
what want.1SG.PRT study and can.1SG.PRT work from
lo que estudié
that which study.1SG.PRT

'You see there are women who are lucky, but to me everything has cost. Well I have studied what I wanted and I have been able to work with what I studied'

Since it has become conventionalized, the form may also contradict the source meaning, and the source and the target may occur side by side. All these elements are present in age group I. See, for instance, example (136), in which 
the Preterit expresses persistent situation, arguably an imperfective notion, far from the original past perfective meaning of the Preterit:

\section{(136) $\quad(14: 38 / 5)$}

$\begin{array}{llllll}\text { En ningún } & \text { momento } & \text { desconfié } & \text { de } & \text { Martín } & \text { para } \\ \text { In no } & \text { moment } & \text { distrust.1SG.PRT } & \text { of } & \text { Martín } & \text { for }\end{array}$

nada, siempre confié en el cien porciento
nothing always trust.1sG.PRT in him hundred percent 'I've never distrusted Martin, no way; I've always trusted him a hundred percent'

As mentioned in the introduction to this chapter, the age group I corpus has only eight Perfect tokens, clearly too few to serve as generalizations (much less so for statistical uses). In the analysis presented here, it is therefore not unexpected to find that the Perfect tokens that do occur in the young and adolescent speakers do so in contexts with no preestablished past context; they are unidentified as to temporal location:

(137) (01:04:43/8)

Yque hashecho de parte de estudiar? Donde And what do.2sG.PRS.PRF from part from study where estás viviendo?

are living

'What have you done besides studying? Where are you living?'

(138) (01:07:25/8)

Noruegos acá no te has comunicado con

Norwegians here NEG you communicate.2SG.PRS.PRF with

noruegos acá?

Norwegians here

'Norwegians, you haven't been in contact with Norwegians here?'

We have observed examples in which it appears that the Preterit is used instead of the Perfect when there is an established past context. HABCULT data correspond to the stage referred to as "transitional contexts." In age group II, the new use appears to have been conventionalized, but it is still not preferred or obligatory. Table 23 summarizes the changes involved in the transitional context. 
TABLE 23 The transitional context allowing for CR interpretation

\begin{tabular}{llll}
\hline Transitional context & Preterit's original use & $\begin{array}{l}\text { Preterit in transitional } \\
\text { context }\end{array}$ & $\begin{array}{l}\text { Preterit's } \\
\text { novel use }\end{array}$ \\
\hline $\begin{array}{l}\text { Out-of-the-blue contexs } \\
\begin{array}{l}\text { With preestablished } \\
\text { time frame }\end{array}\end{array}$ & No & No & Yes \\
$\begin{array}{l}\text { Corresponding speaker } \\
\text { group/material }\end{array}$ & $\begin{array}{l}\text { HABCULT, Age group 2, } \\
\text { introductory texts, } \\
\text { UYCORP }\end{array}$ & $\begin{array}{l}\text { Age group 1, age } \\
\text { group 2, UYCORP }\end{array}$ & Age group 1 \\
& & & \\
\hline
\end{tabular}

Age group I shows a clear preference for the new form and the exclusion of the old one. These gradual stages are compatible with a view of change as originating in microdynamics of pragmatic innovation, which gives rise to constant innovation. The latter may or may not give rise to new conventionalized meanings, but in this case, it has.

\subsection{The "Why": Pragmatic Motivations}

Given the assumption that the Preterit occurs first to express past with CR without temporal specification, and after a past context has been established, as we saw in, for instance, example (122), it can be hypothesized that this pattern illustrates a process to some extent compatible with the assumptions put forward in frameworks such as Traugott and Dasher's (2002), an approach that attempts to intergrate external and internal factors. In this view, also discussed in 2.1.2.3, it is assumed that semantic change occurs through the conventionalization (semanticization) of inferences. The basic idea is that speakers are able to intentionally shape their language and instigate reanalysis and, further, can invite certain pragmatic inferences, volitionally implying the unsaid, subsequently becoming part of the information conveyed. The implicature is in a sense absorbed-semanticized through frequent use. ${ }^{6}$ The new meaning arises via a detour; the sentence may give rise to further information, and

6 Traugott's broad use of implicature is taken to be the result of the invited inference. 
only via this detour can the new meaning arise. The fact that context plays a crucial role in grammaticalization established (Diewald \& Smirnova 2010: 112). Even though the Porteño Spanish expansion is not a grammaticalization, it is difficult to imagine how such a change would be triggered by anything but context (see introduction).

Traugott and Dasher (2002) differentiate three levels of meaning. The coded meaning refers to semantics, the convention of a language at a given time. Utterance-type meanings are generalized invited inferences (GIINs), preferred meanings, and conventions of use in language-specific communities, meanings that may be cancelled by context. Utterance-token meanings are invited inferences (IINS) that have not been crystalized into commonly used implicatures and that arise in context, on the fly. Note that generally, when change occurs, it is in the direction of coded meaning $>$ IIN $>$ GIIN $>$ new coded meaning. This is what might have occurred in Porteño Spanish. It is assumed that the act of speaking (and writing) is governed by a set of principles-heuristics-guiding the choice of the right expression to suggest a specific interpretation and to account for preferred interpretations. These principles are further developments of Grice's original maxims of conversation (Grice 1989) and include the following, here schematically presented (Traugott \& Dasher 2002:18-19): ${ }^{\text {? }}$

- The Q(uantity)-heuristic: "Make your contribution as informative as required, and imply no more thereby." This maxim can retard change, impede inference beyond what is said, and function to preserve and privilege literal meaning.

- The R(elevance)-heuristic: "Say/write no more than you must, and mean more thereby." This is where change occurs, as it may lead to rich interpretations and pragmatic strengthening.

- The M(anner)-heuristic: "Avoid prolixity"; that is, avoid especially marked, complex expressions or "marked expressions." This heuristic may be exploited as old form-meaning pairs are used to mark the content/situation and thus lead to change.

How can such maxims be relevant for the present case? The R-heuristic might to some extent shed light on the development. Recall that the speaker selects not only content but also expression of that content. In this view, it could be

7 Note that Dahl (1985) has a critical discussion on the maxims and their applicability to, e.g., accidence categories. I will not address this discussion for the time being. 
assumed that the speaker uses the Preterit in an innovative way, in which it is detached from the past context and intended to convey past + CR meaning. But why would a speaker use the Preterit to convey CR? Porteño Spanish already had a morphological category expressing CR. This in itself, however, is not an argument against the formation of new categories. This is the norm in language, and note that I reject functionalist explanations for grammatical change and grammaticalization in particular (see Bybee et al. 1994: 297-300 for good discussion).

It is possible that the innovative uses of the Preterit, in which the past context was not specified, exploited the R-heuristics of communicating efficiently, inviting the inference that what is meant is more than what is said (here, the past reference expressed phrase initially), on the assumption that the speaker will not elaborate when less will do.

Note, also, that common motivations for speaker-induced changes such as "speak extravagantly" (Keller 1994) clearly do not apply here. In Keller's view, a speaker may obtain a short-term advantage by using a stronger expression than is warranted by the true circumstances. This is compatible with the assumption that the origins of change can lie in the emergence of new expressions through processes such as increased expressiveness and innovations due to the desire to avoid being misunderstood (Croft 2001: 74-75). Subsequent overuse of such expressions, leading to their devaluation, is common in semantic change, and such inflationary mechanisms may trigger change, in a process reminiscent of the way in which a perfect is used frequently to express CR and subsequently loses semantic components (see Chapter 2). Again, this is not observed in Porteño Spanish; as observed initially, the Preterit becomes able to express more specific semantic content, not the other way around.

It is in fact difficult to imagine how a speaker would obtain any effects from choosing the Preterit over the Perfect. As discussed, an expanding Perfect is often explained by pointing to its $\mathrm{CR}$ component, which increases in frequency and subsequently loses semantic components: an inflationary process such as the one referred to above (see also Chapter 4). In the expansion of a Preterit, no such elements can be pointed to.

Notably, the use of a Preterit instead of a Perfect can be interpreted as an act of economy, or to be "quick and easy," in Slobin's words (1977: 187). In not expressing the past context explicitly, the speaker is being economical, deleting "surface forms and expressions," perhaps in order to communicate a lot of information before the hearer "gets bored or takes over the conversation" (ibid.). This explanation would, however, conflict with the other principles involved in language change, notably the desire for clarity, or, in Slobin's words, 
the desire to "be clear," "be expressive," and "be humanly processible in ongoing time" (ibid.: 186).

\subsubsection{The Lack of Temporal Specification}

So far, focus has been on the speakers and their innovation. Obviously, the hearer plays an important role in the spread of a change; Schwenter and Waltereit (2010), for example, note that the role of the hearer is important because there simply is no way a novel use can be conventionalized if hearers do not perceive the innovation. In this view, a hearer can assume a novel conventional meaning for some element of an utterance, if it deviates from the utterance's literal meaning. The conventionalization and spread to the linguistic community clearly go via hearers, not speakers. In this case, the aim is to provide a hypothesis on how hearers arrive at the $\mathrm{CR}$ interpretation that is today conventionalized in Porteño Spanish. How is this meaning arrived at?

Once the hearer is presented with a Preterit whose intended temporal reference is not set to a defined past moment (either inferred from discourse or explicitly derived from temporal adverbs), she is forced to interpret the utterance in a meaningful way. Here, the fact that she arrives at a CR interpretation might be possible to account for by means of assumptions of optimal relevance (Nicolle 1998; 2011; see Fløgstad \& Falkum 2013 for application to grammaticalization).

Schwenter and Torres Cacoullos (2008) study the distribution of Perfect and Preterits in Penisular Spanish and Mexican Spanish. They argue that the route uncovered, by which hodiernal perfectives become default past tenses, is through the temporally indeterminate contexts. They also find that in Mexican Spanish, the Perfect is most strongly favored when temporal distance is irrelevant, that is, in which temporal anchoring is left unspecified by the interlocutors. The Mexican Perfect, then, is retained in this canonical context. The Porteño Perfect is not, but interestingly, the data here presented suggest that these contexts are precisely where the overlap occurs. A majority of all examples of temporally indeterminate contexts are expressed by means of Preterits. Apparently, temporal indeterminacy may be a context that opens for both expansion toward default past, and toward current relevance interpretation. How can both be true? According to Schwenter and Torres Cacoullos (ibid.: 31) "indeterminate contexts are more open to the generalization of the PP than determinate (specific, definite) temporal reference, due to their lack of temporal anchoring". This explanation for the expansion of a Perfect into a Past or Perfective, is remarkably similar to that provided by Dahl and Hedin (2000) for these context's being the locus of $\mathrm{CR}$ interpretation, to which I now turn. 
7·5.1.1 Perfects and Semantic Interpretation: CR and the Spatio-Temporal Location Constraint

On the same note, Dahl and Hedin (200o) argue that the absence of a temporal specification can produce a CR interpretation. When adverbs are used, the time reference (past) takes over the attention of the temporal point of reference. Sentences that are intended to be used in CR contexts license a breach in the spatiotemporal location constraint, in a process reminiscent of preemption (Boyd \& Goldberg 2011). Preemption is a particular type of indirect negative evidence that results from repeatedly hearing a formulation B in a context where one would expect to hear a semantically and pragmatically related alternative formulation A. Eventually, speakers implicitly recognize B over A as the appropriate formulation. In this case, it is possible to imagine that it is precisely the absence of the adverbial that triggers the CR interpretation. If there is no temporal specification, hearers in a meaning negotiation will do their best to accommodate their interpretation.

More specifically, Dahl and Hedin (2000) note that whether a sentence takes a CR interpretation influences its need for temporal specification. This is the case for, for instance, Russian. In Russian, the use of a temporal adverbial in fact prevents a CR interpretation. This means that in example (139), it is possible that Yeltsin still is in Moscow (Dahl \& Hedin 2000: 394):

(139) El'cin priexal $\quad$ v Moskvu
Yeltsin arrive.PFV.PST in Moscow
'Yelstin has arrived in Moscow'

This interpretation is impossible in (140), according to Dahl and Hedin:

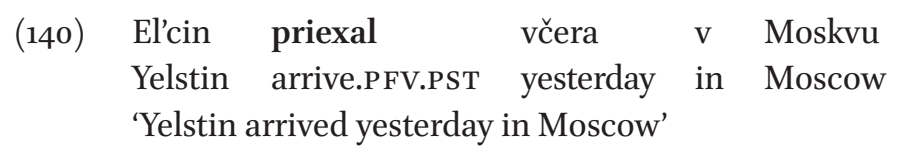

In (139), therefore, it is the absence of an adverbial that makes the CR interpretation possible. The fact that a sentence is intended to have CR meaning licenses a breach in the spatiotemporal constraint. It is possible that a time adverbial shifts the focus of the result to the attention to the past-time situation.

The notion of a breach in the temporal constraint as a trigger of CR interpretation applies particularly well to this case. Recall example (141) repeated below for convenience. Here, the hearer (informant 15) clearly attributes the Preterit a CR meaning, because she replies using a Perfect experiential (he ido). 
(141) (01:35/15/17)

17:

Para allá afuera no fueron a la Concordia?

To there outside NEG go.3PL.PRT to the Concordia

'Out to Concordia you haven't been?'

15:

No no heido

NEG NEG go.1SG.PRS.PRF

'No I haven't been there'

This clearly indicates the CR interpretation of the Preterit. B responds to A's question using the Perfect, clearly interpreting A's Preterit as expressing CR. It is possible that this interpretation is particularly available precisely because of the lack of a temporal adverbial, as in the examples illustrated above.

In addition, it illustrates the variation found in A's speech, as well as B's reanalysis, but also how the novel construction has not reached the level of linguistic expression. Note also that speakers tend to be less aware of changes in morphosyntactic form than they are of phonetic elements, since the latter are concrete and observable, the former abstract entities). It is thus possible to question whether B is aware of A's innovative use of the Preterit.

\subsection{Subfunction Variation as the Key to Understanding the Preterit's Expansion}

So far, I have shown how speakers from all sources except those from age group I exhibit variation between Preterit and Perfect in their expression of experientiality. This variation is taken to be crucial in the understanding of the Preterit's expansion.

In addition, two processes may shed light on the emergence of subfunction variation in the expression of experientiality. One is so-called pragmatic strengthening; the other is the way the lack of temporal specification may trigger the CR reading. It is hypothesized that this change may have started as a pragmatic routine here because this subfunction is semantically closer to the Preterit category that replaces it. It is difficult to imagine how a form expressing persistent situation, for example, could occur in a context in which the expression of CR would become inherent to it. How could the imperfectivity expressed by this form be inferred in the verb, with no explicit expression? 
I take the lack of variation found in this subfunction in the oldest sources to illustrate the unlikelihood of this option. There is variation between Perfect and Present constructions to express persistent situation in the oldest sources. One could imagine this Present construction expanding, but such expansion is not observed in the younger speakers.

\subsubsection{A Note on Variation}

The subfunction variation in Porteño Spanish illustrates a pervasive and ubiquitous morphosyntactic variation, similar to phonological variation (Croft 2010) or gradualness (discussed in Chapter 2). The variation found in one subfunction may have spread to other subfunctions through microsteps. It is also shown that these microsteps have gone to completion in the language of young and adolescent speakers of Porteño Spanish, but it is also stressed that it need not (as in, e.g., the current Mexican system; see 4.3.1). Finally, I discuss whether contact has played a part in the Preterit's spread through society, assuming, as Blythe and Croft do (2012), that innovation is triggered by language use (here, this refers to the emergence of the possibility to express past with CR by means of Preterits), while the further spread has a social component (here, this refers to the Preterit's spread throughout society).

Croft (2010), in a study of different verbalizations of the so-called Pear Story, notes that his data do not provide evidence in favor of the assumption that new, analytic forms tend to expand at the expense of old, synthetic forms. This is particularly relevant to the present case. Recall that the Preterit is a synthetic, irregular form, as opposed to the analytic, more regular Perfect. Croft still argues that frequency is the main force behind change. In certain contexts, he argues, as the old and the new form compete in a synchronic variation, the frequency of the old form may be just as high as that of the new emerging form, making the expansion of the former just as likely as the expansion of the latter. Such expansion is likely to have been the case in Porteño Spanish's age group II. Both Preterits and Perfects were used to express past with CR. Given Croft's observation that there is no determinacy in whether analytic or synthetic forms expand, both forms can be as likely to expand. In Porteño Spanish, the Preterit has.

\subsubsection{Microsteps}

The different data samples here presented provide different synchronic pictures of Porteño Spanish. Other Latin American varieties also show heterogeneous distributions (see Chapter 2 and 3). In my view, this variation is not unexpected. These stages are the individual results of microsteps taken 
in diverse directions, all enabled by the intertwined semantic relationship between perfects and pasts. The micro-/macrostep metaphor provides a good illustration of how these changes can go to completion (as in young Porteño Spanish speakers) but need not. Mexican Spanish, for example, has a system in which the Perfect prevails as conveyor of persistent situation (Schwenter 2011); recall the so-called "Latin American norm" discussed in Chapter 3.

As I showed in Chapter 2, microsteps are crucial to the usage-based understanding of the nature of change as gradual, not abrupt. In this view, macrochanges are the result of successions of microsteps. It is important to note that there is no determination assumed once a microstep has been taken: the change need not come to completion. 19th century Argentinean sources may indeed provide evidence for the nondeterminacy of semantic change. I now turn to this.

\subsubsection{A Dead End: Microsteps not Gone to Completion}

A methodologically useful way to begin a diachronic study is to seek evidence in a historical corpus for the transition from an earlier stage to the synchronic one studied, all the while watching for developments that may have deadended (Traugott \& Dasher 2002). Such dead-ended developments frequently show incipient conventionalization of a meaning that is not replicated, or not replicated for any considerable length of time, whereas it may become a highly salient meaning in another language. For example, there is some sporadic evidence of incipient because-meanings for while in Middle English; these meanings never conventionalized in English, but conventionalization did develop for the cognate weil in German.

There is indeed evidence for such a dead end in old Porteño Spanish texts. In a text from 1880 (Sánchez's M'hijo el dotor), there is clear evidence that the Perfect preferred to express past with current relevance, as observed in Table 24 .

TABLE 24 Perfect and Preterit distribution of past with current relevance in Sánchez (1880 [1966])

M'hijo el dotor Experiential Recent past Resultative Persistent situation Total (\%)

\begin{tabular}{lrrrrr}
\hline Preterit & 2 & - & 4 & - & $6(5 \%)$ \\
Perfect & 54 & 4 & 56 & 9 & $123(95 \%)$ \\
\hline Total & 56 & 4 & 60 & 9 & $129(100 \%)$
\end{tabular}


The numbers are striking: Sánchez's play, arguably one that attempts to depict the vernacular of the area, shows clear preference (95\%) for the Perfect. In addition, there is evidence tht the Perfect was also used in contexts previously restricted to the Preterit: prehodiernal (referring to situations occurring before today; see 2.3.4.2), with a specific-time adverbial (for further evidence, see Fløgstad 2007):

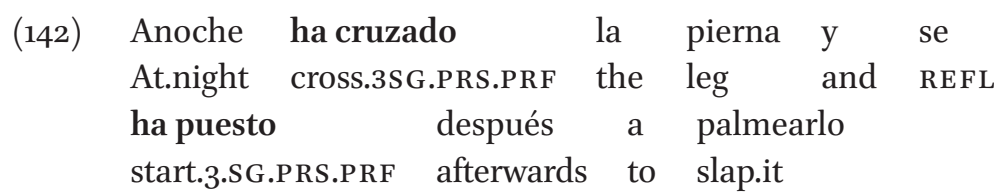

'Last night he crossed his leg and after that he started to applaud it'

(Sánchez 1880 [1966]: 46-47)

Recall also Abeille's early and surprising claim (1900 [2005]), discussed in Chapter 3, that 19th-century Porteño Spanish was characterized by the use of Perfect where other varieties prefer Preterits.

It is well known that only a small subset of novel uses undergoes conventionalization (Ariel 2008: 211; Blythe \& Croft 2012). The developments that have occurred in other Latin American varieties, in which the Perfect to various extents is in use, may therefore be interpreted as having taken different microsteps in various directions.

So far, I have pointed to contexts in which such steps may originate. These sections have provided a tentative analysis of the expansion as being triggered by how language is used. The combination of interviews, crosslinguistic comparisons, and theoretical assumptions suggests a starting point. The functional overlap between the experiential and the Preterit categories is such that the boundaries are fuzzy and easily bleed into each other's domain. Thereby, speakers may exploit pragmatic maxims (here, the R-heuristic), practices that become pragmatic routines and later conventions. In addition, the absence of temporal specification allows the $\mathrm{CR}$ interpretation to be arrived at. Note, however, that contexts that may facilitate change are a necessity, but such contexts are not sufficient for change to occur.

\subsubsection{Further Spread}

Focus thus far has been on the synchronic variation that triggers the expansion of the Preterit in Porteño Spanish - that is, on the first step in the process of change, namely innovation. However, in age group I, the Preterit has spread to all four subfunctions associated with the Perfect: experiential, resultativity, recent past, and persistent situation. The data present two types of evidence 
for how this spread has come about: (1) The Preterit first spreads to experiential, and (2) the Preterit last spreads to persistent situation. Recall that recentpast tokens are practically absent from the corpus, while resultativity shows variation in its expression in age group II. It is possible to imagine an expansion in line with a modified version of Croft's model from section 7.3.2.1:

First to be expressed by means of Preterit

Experiential

$\uparrow$

(Recent past)

$\uparrow$

Resultative

$\uparrow$

Persistent situation

Last to be expressed by means of Preterit

Recent past is placed after experiential because there is no evidence that this function has Preterit expression in other Latin American or Romance varieties. However, according to Croft (2013: 142-143), this is the subfunction that has most in common with a tense, so it is not unlikely that it expands early. The further spread occurs in a process in which an earlier structure is restructured to match an existing one; here, the Preterit is restructured to express not only experientiality but gradually other subfunctions, leading to the Perfect's eventual demise. This gradual expansion occurs at different paces, and as we have seen, there is no assumed determinacy in its completion.

\section{$7 \cdot 7$}

\section{The End Result: The Unstable Perfect}

This section focuses on the macrochange: the full expansion of the Preterit to convey all subfunctions of Perfect among Porteño Spanish speakers.

A disappearing perfect is in itself not newsworthy, and the perfect is known to be an unstable category (Lindstedt 2000). Crucially, however, the perfect is assumed not to disappear but to become something else, as the European Perfect $>$ Past expansion clearly shows. One important finding of this study is that this instability should not be interpreted as being related to the specific perfect category; rather, the instability should be viewed as having to do with the instability of the distinction. The intertwined relationship between Perfects and Preterits leaves room for functional overlaps that in turn enable the expansion of both. When the microchanges these overlaps lead to provoke macrochanges, it can be observed that the end result is the same as that occur- 
ring at the level of semantic categories in languages in which a Preterit and a perfect expand. The nature of the microsteps is not identical. But the result of the macrochange is: the loss of one category and the expansion of the other. The surviving category comes to convey both perfective function and past with CR. In French, it is the old Perfect that conveys both perfective and past with CR.

French:

Perfect > Past perfective and past perfective with CR

Porteño Spanish:

Preterit > Past perfective and past perfective with CR

Dahl (1985: 139) claims that it is not uncommon for a perfect to develop into a perfective and notes that this has happened in a number of Romance languages, such as French. He suggests that one explanation for this tendency is that peripheral tense/mood/aspect (TMA) categories tend to be attracted toward the center of the TMA system, thereby acquiring properties that are typical of the central categories. This observation, he argues, may provide an explanation for the general tendency for grammaticalized expressions of perfect to disappear.

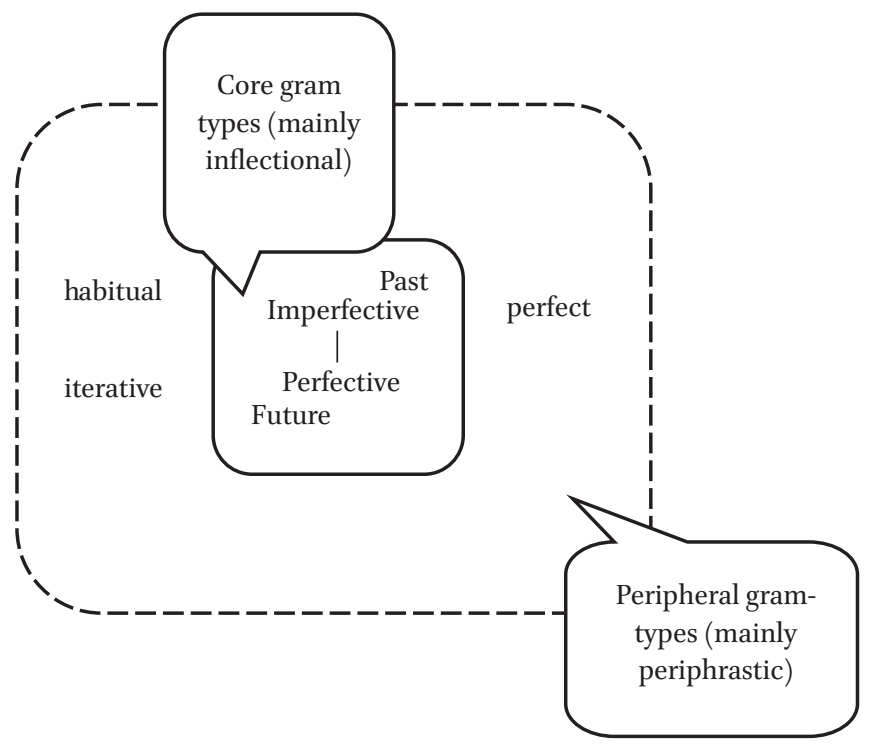

FIGURE 16 The center of the TMA system, simplified after Dahl (1985:139; 2000: 15). 
On the category level, we are clearly dealing with a simplification. Semantically, however, the result of the change is more difficult to interpret. Here, I briefly discuss the semantic process involved in the change.

\subsubsection{Loss vs. Gain, Broadening vs. Narrowing}

The generalization of a Perfect to a past/perfective (as seen in, e.g., French) is often assumed to be a generalization of meaning and a loss of specific meaning components, since it is assumed that the CR component disappears (see Bybee et al. 1994; Heine \& Kuteva 2006; discussion in Chapter 4). This view is in accord with the assumption that increased frequency of use leads to semantic bleaching, which is particularly prevalent in Bybee's view of meaning change in grammaticalization (Bybee 2010). When a perfect expands, therefore, it is usually argued that the CR component is lost and that the category loses specific restrictions. The remaining category is argued to be broader and to have less specific meaning components. In this sense, there is clearly talk of both a frequency-driven bleaching or generalization of meaning, or "loss."

In my opinion, however, it is overlooked that the end result of the expansion of Perfects, such as in French, does not only entail loss. When the Perfect expands, it is not the case that it ceases to express past with CR. Rather is it used both to express this notion as well as past perfective. In this sense, the outcome is strikingly similar to the end result of the expansion of the Preterit in Porteño Spanish.

In this sense, it appears to be most fruitful to define the Porteño Spanish change as a broadening or strengthening since the possibility to express $\mathrm{CR}$ is added to the category scope (Traugott 1988). In addition, the previous restriction on the Preterit, that it required a specific time frame, is also lost, allowing for a broader temporal scope. In a sense, the category has experienced both the addition of specific semantic components and semantic broadening. The remaining Preterit is both more general and more able to express a wider array of functions-among them the specific CR component.

\subsubsection{Summary of Analysis}

I have proposed that the experiential served as the turning point for the expansion of the Preterit in Porteño Spanish and that this function is where Preterit first was used to convey past with CR. I have argued for this both on the basis of the variation found in the experiential (and less so in other subfunctions) in the materials collected for this study, and also through other linguistic sources providing similar evidence, combined with theoretical insights about the nature of the experiential and its relationship to pasts and perfectives. In addition, I have shown that this variation in the expression of this function may have 
arisen through conventionalization of inference and that the hearer reanalysis has come about through a breach in the temporal constraint on the Preterit. Together, these mechanisms allow for a variation in the expression of past with $\mathrm{CR}$, which in turn allows for the expansion of the Preterit. I have stressed that such developments do not necessarily lead to macrochanges; they may indeed constitute microchanges only, which may account for the substantial variation found in the Latin American varieties. This model allows for the following:

- It provides an account for the variation in experiential/recent past (functional overlap) and the lack of such in persistent situation (less semantic overlap).

- It suggests why certain Latin American varieties still preserve the Perfect in persistent situation (e.g., Mexican; see Squartini \& Bertinetto 200o) and explains the general heterogeneity of the Latin American varieties.

- It provides a usage-based explanation without alluding to predictions of form and meaning correlations in paths of development.

\subsection{Contact? A Note on the Further Spread and its Causes}

So far, the question of how the Preterit got passed on to society, and subsequently spread to the language as a whole, has not been treated. As briefly discussed in Chapter 2, I assume that the mechanisms behind innovation are largely language internal (such as, for instance, the mechanisms behind the emergence of variation in the expression of past with CR) but that the further propagation into society clearly has a social part. I now provide a brief discussion of whether contact may have accentuated the Preterit's spread in Porteño Spanish.

As discussed in Chapter 3 (see also Fløgstad 2014), Argentina received more than four million immigrants between $185^{\circ}$ and 1930, an immigration wave that peaked around the turn of the 2oth century, with almost half of the population in Buenos Aires being of non-Argentinean decent. Given the fact that this radical change in the demographics of the Porteño Spanish population appears to coincide with the time span of the change (see Chapter 6 for agebased variation), a note on contact is pertinent. A discussion of contact is also pertinent because Argentinean Spanish (but note, not Uruguayan Spanish) is assumed to be the Latin American Spanish variety in which the expansion of the Preterit has gone the furthest, combined with the fact that Buenos Aires also was the urban center in this region that experienced the most intense level of contact. 
In this section, I discuss whether the expansion of the Preterit (i) was the result of contact of direct transfer from Sicilian Italian (knowing that these scenarios, i.e., influence from immigrant language on the language to which immigrants shift, tends to be rather rare; Sankoff 2001) or (ii) occurred indirectly as a postcontact simplification, generated by adult immigrants' imperfect learning.

As discussed in Chapter 4, the expansion of a perfect has been explained by pointing to its $\mathrm{CR}$ component, which makes speakers use this form more frequently in order to add relevance to their contribution (Bybee et al. 1994: 86). In Porteño Spanish, however, it is the Preterit that has expanded, and the possibility to express $\mathrm{CR}$ has been added to its semantic scope. How can this spread be accounted for? As, for instance, Thomason (2001) notes, contact may be a source of change if it is less likely that the change would occur outside the contact situation. Following predictions from grammaticalization theory, the expansion of a Preterit is indeed unexpected. Therefore, it is relevant to ask whether there are any factors idiosyncratic to Porteño Spanish that may account for the expansion.

\subsubsection{Contact with Sicilian}

Italians made up half of the immigrant population in Buenos Aires, which in 1887 constituted almost half of the entire population in Buenos Aires. Southern Italian immigrants made up almost half of the Italian immigrant population (see details below). Coincidentally, in Sicilian, the Preterit is used more frequently than it is in other Italian varieties, and the Perfect is rare (Harris \& Vincent 1988; Squartini 1998). Crucially, this is not a novel use in Sicilian. Rather, it is assumed to be an archaic feature and the result of the Perfect never properly developing in this variety. It is therefore likely that Sicilian immigrants spoke a variety in which the Perfect was highly restricted. Can contact with Sicilian have triggered the use of Preterit in contexts previously restricted to Perfects in Porteño Spanish?

This type of change would correspond to the notion of borrowing: "the incorporation of foreign features into a group's native language by speakers of that language" (Thomason \& Kaufman 1988: 37). In this view, the native language changes owing to incorporation of new elements. If such a contactinduced change has occurred, it is likely that elements other than the one in question were also transferred from language to language (Thomason 2001). "Invariably (...) in a borrowing situation the first foreign elements to enter the borrowing language are words," argue Thomason and Kaufman (1988: 37). Changes in the sound system generally require strong cultural pressure from 
source-language speakers on speakers of the borrowing language. We find both elements in Porteño Spanish; lexically and prosodically, the Italian impact is unquestionable, and the intonation pattern is argued to have changed because of contact with Southern Italian varieties specifically (see 3.3.2.4). This impact, combined with the fact that the time span of the change seems to coincide with the initiation of the spread, may call for a contact explanation.

Theoretical and demographic considerations, however, seem to disfavor a contact hypothesis. The rapid shift to Spanish did not give rise to a long period of bilingualism, usually a prerequisite for structural change (see, e.g., Sankoff 2001: 641-642; Thomason 2001). In addition, the influence of immigrant language on the language to which immigrants have shifted tends to be restricted. Sankoff (2001: 656) describes how the Norse invasion of England led to morphological changes in the receiving language caused by the newcomers, but notes how this is a rare change, made possible only because of the massive numbers of the newcomers and the intimacy of the contact between them and the pre-existing population. Further complicating the picture is the fact that the Porteño Spanish case does not represent a morphological or syntactic change in itself; rather, it is a change in semantic restrictions, leading to category change. A growing body of research in grammaticalization does point to the fact that grammaticalizing constructions (and thus changing semantic and functional restrictions on constructions) may spread because of contact (Heine \& Kuteva 2006); however, this process also seems to apply to areas in which long-term bilingualism has been found.

However, the main question may be demographic rather than linguistic. The Italian immigrants came primarily from two parts of Italy: from Piedmont, situated in the northwest, and from the south, that is, Sicily and Calabria (Baily 1999: 62). Before 1900, about $50 \%$ of the Italians that immigrated were from the north, but after 190o, the tendency changed and the number of immigrating southerners increased from about $39 \%$ to comprise over $50 \%$ of the total of Italian immigrants to Argentina.

Despite this, it is in fact the Ligurian Italian variety, and especially Genovese, that is argued to have had the most lexical influence on Porteño Spanish and that also is assumed to form the lexical base for Lunfardo (see 3.3.2.5) (Gobello \& Olivieri 2005). In Ligurian Italian, the opposite distribution to that in Porteño Spanish is found: the Perfect has expanded to perfective, as in, for instance, spoken French (Squartini 1998). Another piece of evidence comes from theater plays. Sánchez (1880 [1966]), in a play imitating Italian immigrant language, frequently includes the Perfect, as in the phrase $\mathrm{Ha}$ capito (It. 'Has understood'), Ha comprendido (Sp. 'Has understood'), perhaps 
indicating that the Perfect did indeed exist in the Sicilian immigrants' language to the extent that this was included when imitating them. ${ }^{8}$

Still, since prosodic features present in Sicilian Italian have been passed on to form part of Porteño Spanish, influence from this group clearly has occurred. This may be a typical case of covert prestige; recall that Sicilian immigrants' economic, social, and cultural statuses generally were seen as low. The demographic profile of Sicilian immigrants (they were typically single, young males) would in addition conform to the assumption that a variable is weighted in terms of whether it is used by nonconforming but socially mobile individuals (Labov 2001: 511-518).

In sum, the typological proximity between Spanish and Italian would facilitate structural change, but the short period of bilingualism would suggest lexical/phonological impact only-which is precisely what is found. I therefore assume that the uncertainty of the demographic data, combined with the short period of bilingualism, makes a contact explanation less likely. What cannot be excluded, however, is the possibility of multiple causation, with contact's intensifying a change that was likely to occur anyway. Such intensification has happened, for instance, in the Spanish spoken in Los Angeles, in which a common process toward the loss of the subjunctive category has merely been accentuated by contact with English (Silva-Corvalán 1994).

It should be noted that a contact-induced further spread of the Preterit would be particularly compatible with Blythe and Croft (2012). Their model is highly complex, and here I will only note that they argue that innovation (their term is "first-order variation") comes about through language-internal processes (compatible with, e.g., the mechanisms proposed for the expansion of the Preterit). Crucially, however, they see the further spread throughout society (second- and third-order variation) as being socially conditioned through, for instance, processes of covert prestige.

\subsubsection{Buenos Aires: A High-Contact Society? Categorical Simplification as a Postcontact Phenomenon}

In this section, I briefly discuss the Porteño Spanish data in light of the hypothesis that societal structure correlates with linguistic structures and that distribution of linguistic features is not just areal or random (McWhorter 2011; Trudgill 2011). Trudgill (2011) argues that certain societies and social structures

8 Östen Dahl (personal communication) suggests that hypercorrection toward what is perceived as a local norm may lead newly arrived immigrants to the overuse of a Preterit in all functions. 
(and thus the degree of contact-induced change) tend to be associated with certain linguistic structures, even when we are not dealing with processes such as creolization and pidginization, in which this is well-known. This corresponds to the concept of interference through shift (Thomason \& Kaufman 1988: $38-39$ ), which involves a group of speakers that shift to a different language but fail to learn the target language perfectly. The errors made by the group of learners spread to the native speakers of the target language. In this view, phonological and syntactic features are thought to interfere before lexical ones.

The idea is that noncultural features of a society correlate with structural (nonlexical) features of a language. Such features defining a society may be community size, density of social networks, social stability versus instability, and degree of contact versus isolation. In large, unstable communities, with dense social networks and a high degree of contact, this contact is typically short-term and/or involves imperfect language learning by adults (the inability to learn certain aspects of the language, those which are "L2-difficult," according to Dahl 2004). These communities are where change tends to occur rapidly and where different types of simplification associated with pidginization may occur. The deciding factor is not, therefore, the society per se but rather the presence (or not) of past-threshold learners (McWhorter 2011).

Buenos Aires was clearly a high-contact society around 1900, experiencing short-term, intense contact. It was not a case of long-term contact involving childhood (therefore proficient) bilingualism: as observed in Chapter 3, the shift from immigrant languages to Spanish was rapid. In addition, the demographic information on the immigrants that entered Buenos Aires and Argentina confirms that a majority of those who arrived were indeed past-threshold learnersthat is, adults well past the critical age for language acquisition; $80 \%-85 \%$ were males of prime age (Sánchez-Alonso 200o). The immigrants did not speak only languages typologically proximate to Spanish but also spoke, for instance, Arabic, German, Polish, and Russian (see 2.1).

The change in the use of the Preterit in Porteño Spanish is indeed a simplification in the sense that two categories have been reduced to one. Formally, however, the expansion of the Preterit has more in common with complexification, as it involves irregularization and an increase in opacity. The Preterit as a category is both more irregular and more opaque than is the Perfect, which it replaces; the Perfect is formed with the auxiliary haber 'to have' and a past participle of the verb, as opposed to the synthetic Preterit. Changes in this direction are rather associated with small, tightly knit societies that are more able to encourage the preservation of norms and the continued adherence to norms, and in which complexity is more readily maintained (Trudgill 2011). 
But while the formal properties of the Preterit may be associated with low contact societies, Buenos Aires certainly was not (and is not) such a society. More importantly, no other grammatical features of Porteño Spanish show signs of simplification due to contact itself (à la pidginization). I therefore assume that it is unlikely that the loss of distinction between Perfect and Preterit in this variety is a postcontact phenomenon, despite Buenos Aires's complying with the criterion of being a society in which such changes tend to occur.

\subsubsection{Uruguayan Data}

As discussed in 6.6, data from Spanish spoken in Montevideo, the capital of Argentina's neighboring country Uruguay may shed additional light on the question of contact. Data from young speakers of Montevideo and Dolores Spanish suggest that there, the Perfect is used more frequently in CR contexts than it is in neighboring Buenos Aires. This difference is also suggested in Henderson (2010). However, demographically, the two cities had features in common. In 186o, Montevideo consisted of $48 \%$ foreigners (compared to $36 \%$ in Buenos Aires). At that time, $28 \%$ of immigrants were Spanish, $27 \%$ Italian, and $22 \%$ French, mainly Basques. These numbers are similar to those of Buenos Aires in 1887 (see section 3.2).

Similarities aside, there also were important differences between the two countries, as discussed in Chapter 3 . Recall that Uruguay soon became a country of transit rather than of permanent settlement. Between 1874 and 1901, only 1,596 foreigners became Uruguayan citizens, and in the decade between 1905 and 1914, the ratio of new immigrants to the total population of Uruguay was only one-tenth of that for Argentina (Finch 1981). This fact may be important in understanding the rapid spread of the Preterit in Buenos Aires Spanish as opposed to in Uruguayan Spanish. In the latter, the expansion of the Preterit appears to be less pronounced, and no features point to structural simplification due to contact.

\subsubsection{Increased Morphological Complexity without Contact}

As mentioned in 7.5, many theories of language change emphasize two competing tendencies: clarity, on the one hand, making speakers produce more analytic forms, and economy, on the other, making these analytic constructions reduce in terms of phonetic substance, causing cyclic analytic-syntheticanalytic alternations. But how clear-cut is this picture really? As I have shown, there are several examples of increased morphological complexity in the development of the Preterit in Romance. Typologically, morphological complexification (in the sense of an increased number of morphological slots in a verbal template) is not uncommon. Gildea and Meira (2014) note that in the 
Cariban language family, changes that lead to both increased and decreased morphological complexity occur. Crucially, such changes are widespread and can occur without contact as an explanation, and they may show that changes in complexity do not show consistent directionality. The complexification observed in Porteño Spanish is of a different type than the ones referred to by Gildea and Meira in that the Porteño Spanish case involves a broadening of semantic scope, as well as preference for an already-existing synthetic form. Still, Gildea and Meira's observation adds to the evidence that complexification may occur spontaneously, without contact.

\subsubsection{Summary of Contact Discussion}

In sum, the inconclusive historical and demographic data make it difficult to conclude whether the expansion of the Preterit has been triggered by contact. I have argued that a semantic/pragmatic motivation is more likely for the initial expansion of the Preterit in Porteño Spanish, but the nature of the further spread may well have a socially conditioned motivation. Such motivations are obvious possibilities for further research. 